\title{
Ameloblastic Carcinoma Derived From Odontogenic Cyst
}

National Cancer Institute

\section{Source}

National Cancer Institute. Ameloblastic Carcinoma Derived From Odontogenic Cyst. NCI

Thesaurus. Code C7497.

A rare, aggressive malignant tumor that originates from an odontogenic cyst in the maxillomandibular region. It combines the histologic features of an ameloblastoma and carcinoma. 